УДК $338.48(477)$

\title{
Марин НЕШКОВ
}

доктор экономики, профессор кафедры экономики и организации туризма, Варненский экономический университет, Болгария, e-mail: neshkov@ue-varna.bg

\section{ПРОДЛЕНИЕ ТУРИСТИЧЕСКОГО СЕЗОНА - СТРАТЕГИЧЕСКИЙ ШАНС ДЛЯ БОЛГАРСКОГО ТУРИЗМА}

Нешков, М. Продление туристического сезона - стратегический шанс для болгарского туризма // Вестник сочиально-экономических исследований : сб. науч. трудов (ISSN 2313-4569); под. ред. : М. И. Зверякова (глав. ред.) и др. Одесса : Одесский национальный экономический университет. 2018. № 4 (68). С. $204-211$.

\begin{abstract}
Аннотация. В статье на основе анализа и экспертных оценок влияния сезонности на деятельность курортных комплексов Болгарии предложены некоторые идеи и решения, которые могут способствовать продлению туристического сезона. Сезонность рассматривается автором как свойство туристических потоков концентрироваться в определённых местах на протяжении небольшого периода времени. С экономической точки зрения она представляет собой повторяющиеся колебания спроса на туристские поездки и, соответственно, услуги гостинии с чередуюшимися пиками и спадами. В качестве отправной точки для исследования рассматриваются особенности проявления сезонности на курортах Республики Болгарии. Методика анализа изменений в туристическом сезоне основана на официальных статистических источниках. Для характеристики сезонных колебаний спроса туристов на услуги мест размещения используются универсальные и количественно измеримые показатели, в частности: ёмкость базы размещения (количество коек в местах размещения (МР); потенциильные возможности коечного фонда (количество койко-дней, реализованных в течение одного года или туристического сезона); фактическое использование ёмкости мест размещения (количество реализованных ночёвок, степень занятости коек в МР, соотночение количества койкодней и количества ночёвок). На основе анализа и оценки влияния сезонности на деятельность курортных комплексов Республики Болгарии автором предлагаются некоторые стратегические решения по продлению туристического сезона. К ним относятся: диверсификация болгарского туристического продукта с целью увеличения в нём доли круглогодичных видов туризма; расиирение и реструктуризачия спроса на рынке болгарских туристических продуктов за счёт привлечения туристов из новых перспективных отправляющих регионов, таких как Китай, Индия, Япония и Вьетнам, разработка специализированных продуктов для таких целевых сегментов рынка как туристы «третьего возраста» и посетители с ограниченными физическими возможностями и особыми потребностями. Необходимо также усовершенствование территориального управления и регулирования развития туризма в Болгарии, системы статистического наблюдения и отчётности по результатам туристической деятельности. Разработанные предложения направлены на увеличение объёма и времени предоставления туристических услуг в курортных комплексах Республики Болгарии.
\end{abstract}

Ключевые слова: туристический сезон; места размещчения туристов; ёмкость мест размещчения; коечный фонд гостиниц; диверсификация туристического продукта.

\section{Марін НЕШКОВ}

доктор економіки, професор кафедри економіки та організачї туризму, Варненський економічний університет, Болгарія, e-mail: neshkov@ue-varna.bg

\section{ПРОДОВЖЕННЯ ТУРИСТИЧНОГО СЕЗОНУ - СТРАТЕГІЧНИЙ ШАНС ДЛЯ БОЛГАРСЬКОГО ТУРИЗМУ}

Нешков, М. Продовження туристичного сезону - стратегічний шанс для болгарського туризму // Вісник сочіально-економічних досліджень : зб. наук. праць (ISSN 2313-4569); за ред. : М. I. Звєрякова (глав. ред.) та ін. Одеса : Одеський національний економічний університет. 2018. № 4 (68). С. 204-211.

\begin{abstract}
Анотація. У статті на основі аналізу та експертних оцінок впливу сезонності на діяльність курортних комплексів Болгарії запропоновані деякі ідеї та рішення, які можуть сприяти продовженню туристичного сезону. Сезонність розглядається автором як властивість туристських потоків концентруватися в певних місиях протягом невеликого періоду часу. 3 економічної точки зору вона являє собою повторювані коливання попиту на туристські поїдки $i$, відповідно, послуги готелів з піками і спадами, які чергуються. У якості відправної точки для дослідження розглядаються особливості прояву сезонності на курортах Республіки Болгаріі. Методика аналізу змін в туристичному сезоні заснована на офіційних статистичних джерелах. Для характеристики сезонних коливань попиту туристів на послуги місць розміщення використовуються універсальні і кількісно вимірювані показники, зокрема: ємність бази розміщення (кількість ліжок в місиях розміщення (MP); потенційні можливості ліжкового фонду (кількість ліжко-днів, реалізованих протягом одного року або туристичного сезону); фактичне використання ємності місиь розміщення (кількість
\end{abstract}


реалізованих ночівель, ступінь зайнятості ліжок в МР, співвідношення кількості ліжко-днів $i$ кількості ночівель). На основі аналізу та оцінки впливу сезонності на діяльність курортних комплексів Республіки Болгарії автором пропонуються деякі стратегічні рімення щзодо подовження туристичного сезону. До них належать: диверсифікація болгарського туристичного продукту з метою збільшення в ньому частки цілорічних видів туризму; розширення та реструктуризаџія попиту на ринку болгарських туристичних продуктів за рахунок залучення туристів із нових перспективних регіонів таких як Китай, Індія, Японія $i$ В 'єтнам; розробка спеціалізованих продуктів для таких иільових сегментів ринку, як туристи «третього віку» та відвідувачі з обмеженими фізичними можливостями та особливими потребами. Необхідним є також удосконалення територіального управління та регулювання розвитку туризму в Болгарії, системи статистичного спостереження та звітності за результатами туристичної діяльності. Розроблені пропозиції спрямовані на збільшення обсягу та часу надання туристичних послуг в курортних комплексах Республіки Болгарії.

Ключові слова: туристичний сезон; місия розміщення туристів; ємність місиь розміщення; ліжковий фонд готелів; диверсифікаиія туристичного продукту.

\title{
Marin NESHKOV
}

Doctor of Economics, Professor of Economics and Tourism Department, Varna University of Economics, Bulgaria, e-mail: neshkov@ue-varna.bg

\section{EXTENSION OF THE TOURIST SEASON - A STRATEGIC CHANCE FOR BULGARIAN TOURISM}

Neshkov, M. (2018). Extension of the tourist season - a strategic chance for Bulgarian tourism. Ed.: M. Zveryakov (ed.in-ch.) and others [Prodlenie turisticheskogo sezona - strategicheskiy shans dlya bolgarskogo turyzma; za red.: M. I. Zvieriakova (gol. red.) ta in.], Socio-economic research bulletin, Visnik social'no-ekonomičnih doslidžen' (ISSN 2313-4569), Odessa National Economic University, Odessa, No. 4 (68), pp. 204-211.

\begin{abstract}
The article proposes some ideas and solutions that can contribute to extension of the tourist season, based on the analysis and expert assessments of seasonality effect on the Bulgarian resort complexes activity. Seasonality is considered by the author as a property of tourist flows concentrate in certain places for a short time period. From an economic point of view, it represents repeated fluctuations in the demand for tourist trips and, consequently, hotel services with alternating peaks and troughs. As a starting point for the study, the features of seasonality in the resorts of the Republic of Bulgaria are considered. The method of changes analysis in the tourist season is based on official statistical sources. To characterize the seasonal fluctuations in the tourists demand for accommodation services, universal and quantitative indicators are used, in particular: the capacity of the accommodation base (the number of places in the accommodation sites; the potential capacity of bed accommodation (the number of bed days sold during one year or the tourist season); actual use of accommodation capacity (the number of overnight stays, the occupancy rate of beds in accommodations sites, the ratio of bed-days number and number of nights). The author proposes some strategic solutions for extending the tourist season, based on the analysis and assessment of seasonality impact on the resort complexes activity of the Republic of Bulgaria. These include: diversification of the Bulgarian tourist product in order to increase the share of year-round types of tourism in it; expanding and restructuring demand in the market of Bulgarian tourism products by tourists attracting from a new promising sending regions, such as China, India, Japan and Vietnam, specialized products developing for such target market segments as the «third age» tourists and visitors with disabilities and special needs. It is also necessary to improve the territorial management and tourism regulation development in Bulgaria, the system of statistical monitoring and reporting on the tourist activity results. The developed proposals are aimed at increasing the volume and time of tourist services in the resort complexes of the Republic of Bulgaria.
\end{abstract}

Keywords: tourist season; tourist accommodations; tourist accommodation capacity; bed capacity of hotels; diversification of tourist product.

JEL classification: $L 830$

Постановка проблемы в общем виде. Сезонность является неотъемлемой и объективной особенностью деятельности предприятий в ряде секторов экономики. Ее негативное влияние в туризме вызывает трудности и проблемы в регулировании туристической деятельности, поэтому она была и остается предметом внимания, как со стороны науки о туризме, так и с позиции хозяйственной практики. Основной целью комплексных исследований этого влияния является изучение возможности ограничения сезонности и продления туристического сезона.

Для болгарского туризма проблемы сезонности имеют стратегический характер из-за сильно выраженного моноструктурного развития его продуктовой и территориальной 
структуры. В последние годы они углубляются из-за отсутствия эффективной политики противодействия этому явлению.

Анализ исследований и публикаций последних лет. Сезонность в туризме рассматривается в специализированной литературе как одна из серьёзных проблем развития современной туристической отрасли. Соответственно, поиску путей её решения посвящено немало публикаций болгарских и зарубежных учёных. Так, С. Ракаджийска систематизировала факторы сезонности, которые вызывают значительные колебания туристических потоков; разработала и обосновала рекомендации по снижению негативного влияния сезонности на предприятиях сферы туризма [1]. Считаем, что интересными и профессиональными являються исследования В. Герасименко и О. Милашко, итогом которых стали методы статистической оценки сезонних колебаний спроса на туристических предприятиях [2]. Результаты перечисленных исследований создают основу для дальнейших разработок в данной области, в частности, для анализа потенциальных возможностей продления туристического сезона в курортных комплексах Республики Болгарии.

Выделение нерешенных ранее частей общей проблемы. Анализ результатов исследований учёных-экономистов относительно возможных путей преодоления сезонности в туристической отрасли указывает на необходимость углубления научного анализа изменений в продолжительности туристического сезона на протяжении достаточно длительного периода. Важным также представляется приложение результатов такого анализа к конкретным туристическим дестинациям.

Постановка задания. Целью статьи является разработка идей и решений для расширения туристического сезона путем анализа и экспертной оценки проблем сезонности на курортах Республики Болгарии. Для реализации указанной цели поставлены следующие задания:

- краткое изложение методики исследования сезонности;

- анализ и оценка изменений в продолжительности туристического сезона и степени его использования в Республике Болгарии;

- разработка рекомендаций по формированию эффективной политики и мер по продлению сезона и увеличению занятости коечного фонда в болгарском туризме.

Изложение основного материала исследования. Для целей исследования сезонность в туризме определяется как процесс периодически повторяющихся изменений характеристик явления из-за воздействия комплекса (как правило, аналогичных или одинаковых) факторов.

Некоторые из них объективны, и их влиянием трудно овладеть и эффективно управлять. Другие связаны с туристическим спросом и предложением и более восприимчивы к управленческому воздействию [3]. Именно на них сосредоточено внимание в настоящем исследовании. Все они оказывают негативное влияние на туристическую деятельность, ее управление и эффективность, рациональное использование туристических ресурсов, качество и конкурентоспособность туристического продукта.

Сезонность в туризме имеет ряд особенностей, изучение которых в конкретном туристическом месте является необходимым условием для продления периода активной туристической деятельности. В частности, для Болгарии они отличаются несколькими важными позитивными и негативными проявлениями, прямо связанными с расширением туристического сезона.

Первая - это благоприятное географическое положение страны и чрезвычайно богатый потенциал природных и климатических условий, которые можно считать конкурентными преимуществами по сравнению с другими подобными туристическими направлениями. Это создает хорошие условия для развития морского туризма в период до шести месяцев, горного туризма с двумя сезонами, диверсификации туристического предложения, оптимизации территориальной структуры туризма. Рассматриваемая характеристика подразумевает создание комплексного и конкурентного продукта в четырех сезонах года с благоприятным соотношением цены и качества. 
Вторая характеристика касается усвоения и использования природных и антропогенных туристических ресурсов. Она конкретизируется в территориальной концентрации туристических ресурсов и продуктов, отсутствии или несовершенном правовом регулировании территориальной структуры туризма, урбанизации туристических регионов и низкой эффективности болгарского туризма.

Третья характеристика выражается в неконтролируемой застройке традиционно используемых курортных зон и ускоренном увеличении пропускной способности коечной базы. Опрос, проведенный в 14 муниципалитетах на болгарском черноморском побережье в 2008 году, показал, что максимальная емкость коечного фонда в этом районе составляет около 600 тысяч единиц, которая в 2007 году была использована чуть более 50\% (около $30 \%$ для Северного и 65\% для Южного побережья Черного моря). Болгарские эксперты в области туризма считают, что общее число мест размещения (MP) туристов в местах проживания, в целом по стране превышает один миллион единиц. Данные экспертов значительно превышают цифры по количеству мест размещения туристов, которые приводятся в официальной статистике национальным статистическим институтом Болгарии.

Четвертая характеристика связана с неустойчивым развитием болгарского туризма, которая объективно ограничивает возможности его воспроизводства путем эффективного использования туристических ресурсов.

Пятая характеристика относится к туристическому потреблению, которое в результате негативных тенденций развития туризма во время переходного периода значительно поменяло свой характер и структуру. В девяти основных курортных комплексах Болгарии устойчиво доминирует доля ночевок иностранных посетителей. Она существенно превышает удельный вес ночевок болгарских туристов и в 2017 году достигла 87\% от общего числа ночевок всеми туристами [4]. Увеличивается и доля низкоплатежеспособной клиентуры при сохранении моноструктуры по национальности туристов, что стимулирует негативное влияние сезонности.

Методика анализа изменений туристического сезона в данном исследовании основана на официальных статистических источниках. Для ее объективации были использованы универсальные и поддающиеся количественной оценке показатели: емкость базы размещения (количество коек в местах размещения (МР); потенциальные возможности коечного фонда (количество койко-дней, реализованных в течение одного года или туристического сезона); фактическое использование емкости мест размещения (определяется такими показателями как: продолжительность туристического сезона в днях, количество реализованных ночевок, степень занятости коек в МР, соотношение количества койко-дней и количества ночевок). Анализ перечисленных показателей ограничен периодом после 2010 года, из-за отсутствия систематизированной и сопоставимой статистической информации в предыдущие годы.

Анализ продолжительности туристического сезона в Республике Болгарии и поиск возможностей для его продления все более утверждается как объективная потребность. Это определяется преобладающей долей сезонных видов туризма в последние десятилетия. К 2017 году около 68\% коечного фонда в МР и более 66\% от количества ночевок сосредоточено в трех прибрежных районах (Добрич, Варна и Бургас), где доминирует морской туризм [5]. Если к этим цифрам добавить также горные курорты национального значения, где преобладает другой основной сезонный туризм - горный $(8,1 \%$ коечного фонда соответственно и 16,2\% ночевок), то получим приблизительную общую долю сезонных видов туризма в $70 \%$ и $82 \%$ соответственно для обоих показателей. Считаем, что она может быть завышенной как минимум на 5\% за счет других областей, где также развиты такие виды туризма. Таким образом, количественно измеряемое влияние сезонности в Болгарии может быть установлено на уровне 87-90\% [5].

Данные в табл. 1 дают общее представление о динамике некоторых ключевых показателей в деятельности мест размещения в стране, с помощью которых мы определяем степень их ежегодной занятости, усредненную для всех видов туризма. На их основе был 
сделан вывод о том, что она колеблется в течение периода исследования между 26\% в 2010 г. и $39 \%$ в 2017 году.

Таблица 1

Динамика мест размещения туристов и их занятость в период 2007-2017 гг. (рассчитано автором на основе данных [4; 5] за 2007-2017 гг.)

\begin{tabular}{|c|c|c|c|c|c|c|c|c|c|c|}
\hline \multirow{2}{*}{ Годы } & \multicolumn{2}{|c|}{ MP } & \multicolumn{2}{|c|}{ Коечный фонд } & \multicolumn{2}{|c|}{ Ночевки в МР } & \multicolumn{2}{|c|}{ Койко-дни } & \multicolumn{2}{|c|}{$\begin{array}{c}\text { Занятость, } \% \\
(6 / 8)\end{array}$} \\
\hline & кол-во & $\begin{array}{c}\% \\
\text { изм. }\end{array}$ & $\begin{array}{l}\text { тыс. } \\
\text { ед. }\end{array}$ & $\%$ изм. & тыс.ед. & $\%$ изм. & тыс. ед. & $\begin{array}{c}\% \\
\text { изм. }\end{array}$ & $\%$ & $\begin{array}{c}\% \\
\text { изм. }\end{array}$ \\
\hline 1 & 2 & 3 & 4 & 5 & 6 & 7 & 8 & 9 & 10 & 11 \\
\hline 2007 & 3276 & 100,0 & 270,8 & 100,0 & 16303 & 100,0 & 48220 & 100,0 & 33,8 & 100,0 \\
\hline 2010 & 3540 & 108,0 & 283,6 & 104,7 & 16261 & 99,7 & 61997 & 128,6 & 26,2 & 77,5 \\
\hline 2012 & 2758 & 84,2 & 301,1 & 111,2 & 20252 & 124,2 & 56211 & 116,6 & 36,0 & 106,5 \\
\hline 2013 & 2953 & 90,1 & 302,4 & 111,7 & 21617 & 132,6 & 58740 & 121,8 & 36,8 & 108,9 \\
\hline 2014 & 3163 & 96,6 & 314,3 & 116,1 & 21698 & 133,1 & 61396 & 127,3 & 35,3 & 104,4 \\
\hline 2017 & 3346 & 102,1 & 348,7 & 128,8 & 26054 & 159,8 & 66468 & 137,8 & 39,2 & 116,0 \\
\hline
\end{tabular}

Следует уточнить, что занятость гостиниц рассчитывается в соответствии с официальной методикой Евростата и Национального статистического института Болгарии как отношение количества ночевок на число койко-дней в эксплуатационный период, т.е. в расчет не включается время, когда средства размещения не функционируют. Однако, считаем, что при таком подходе утрачивается реальное представление о фактической занятости мест размещения туристов. Ни один собственник или инвестор в своих бизнеспланах не может исключить время, когда бы он не получал доходы, но в то же время покрывал бы проценты по кредитам или нес бы какие-либо постоянные расходы.

Такого заблуждения или ошибочного представления можно избежать путем пересчета и исправления официально зарегистрированного в статистических таблицах количества койко-дней, отражающих реальное «время существования» (а не функционирования) мест размещения в течение года. Более корректные данные можно получить, если умножить количество мест в гостиницах на число дней в году, т.е. на 365 дней. Так, если воспользоваться данными табл. 1 и пересчитать занятость средств размещения таким образом, как указано выше, то получим следующие скорректированные значения этих величин - в 2007 г. занятость гостиниц составит - 16,5\%; в 2010 г. - 15,7\%; в 2012 г. - 18,4\%; в 2013 г. - 19,6\%; в 2014 г. - 18,9\% и 2017 г. - 20,5\%. Элементарный арифметический взгляд на цифры из двух динамических рядов табл. 1 и пересчитанных значений показывает, что приблизительная разница между их средними значениями выражается в соотношении 2:1. Именно это соотношение мы будем использовать как условный корректирующий коэффициент для дальнейшего анализа.

В то же время через количество койко-дней мы можем измерить среднюю продолжительность «эксплуатационного сезона», разделив его на количество мест в МР. Данные, которые мы получаем после таких расчетов, будут следующими: в 2007 году средняя продолжительность эксплуатационного сезона составила 178 дней; в 2010 г. - 218; в 2011 г. - 273; в 2012 г. - 187; в 2013 г. - 194; в 2014 г. - 195 и в 2017 г. - 190 дней. Отсюда следует вывод, что эффективное использование коечного фонда в местах размещения в Болгарии намного ниже, чем в конкурирующих дестинациях.

Динамика сезонных колебаний (исходя из данных о реализованных ночевках в стране) показывает что, существенных изменений количества ночевок и конфигурации кривой сезонных колебаний не наблюдается. Сезон болгарского туризма постоянно и четко ограничен периодом с мая по сентябрь и имеет выраженный сезонный пик с середины июля до середины августа. Преобладающее влияние на сезонность оказывает морской туризм. Определяющим для формирования сезонности в Болгарии является поток иностранных посетителей в отличие от болгарского туристопотока, при этом в обеих группах наблюдается аналогичное распределение ночей по месяцам [5]. 
Представление об изменениях и различиях в продолжительности туристического сезона по основным видам туризма (летнем и зимнем, морском и горном) дают данные табл. 2.

Их них видно, что на курортах национального значения, для которых Национальный статистический институт Болгарии ведёт отдельную статистику, не наблюдаются ясно выраженные тенденции, а скорее имеют место разнонаправленные колебания по наблюдаемым показателям в период с 2010 по 2017 года. Вопреки логике, в горных курортах, с двумя сезонами, активная туристическая деятельность короче (например, в Пампорово) при сильной концентрации в течение первых трех месяцев года. В морских курортах она более продолжительная (особенно на «Золотых песках», «Солнечном берегу» и частично в курортном комплексе «Святых Константина и Елены»).

Таблица 2

Динамика занятости (\% 3) и среднего количество дней эксплуатации мест размещения туристов (ДЭ) на курортах национального значения в период 2010-2017 гг. (рассчитано автором)

\begin{tabular}{|l|c|c|c|c|c|c|c|c|c|c|}
\hline \multirow{2}{*}{ Курорты } & \multicolumn{2}{|c|}{2010} & \multicolumn{2}{c|}{2012} & \multicolumn{2}{c|}{2014} & \multicolumn{2}{c|}{2015} & \multicolumn{2}{c|}{2017} \\
\cline { 2 - 14 } & $\% 3$ & ДЭ & $\% 3$ & ДЭ & $\% 3$ & ДЭ & \% 3 & ДЭ & \% 3 & ДЭ \\
\hline Албена & 14,5 & 53 & 21,6 & 79 & 19,7 & 72 & 21,4 & 78 & 19,9 & 73 \\
\hline Боровец & 18,9 & 69 & 21,4 & 78 & 20,3 & 74 & 20,8 & 76 & 27,9 & 102 \\
\hline Дюны & 21,9 & 80 & 35,9 & 131 & 21,9 & 80 & 20,0 & 73 & 25,5 & 93 \\
\hline Елените & 12,6 & 46 & 12,6 & 46 & 11,0 & 40 & 6,6 & 24 & 8,2 & 30 \\
\hline Золотые пески & 18,6 & 68 & 23,0 & 84 & 21,9 & 80 & 20,8 & 76 & 24,4 & 89 \\
\hline Пампорово & 9,9 & 36 & 16,4 & 60 & 17,5 & 64 & 17,0 & 62 & 19,5 & 71 \\
\hline Св. Конст. и Ел. & 23,6 & 86 & 23,3 & 85 & 16,7 & 61 & 15,9 & 58 & 18,9 & 69 \\
\hline Солнечный берег & 18,4 & 67 & 20,8 & 76 & 18,1 & 66 & 21,6 & 79 & 23,6 & 86 \\
\hline
\end{tabular}

Важно отметить также тот факт, что на продолжительность туристического сезона особенно сильно влияют изменения в категорийной структуре мест размещения, что прямо и косвенно подтверждается данными табл. 3. Из них можно сделать определенный и логичный вывод о существовании здесь прямой функциональной зависимости: чем выше категория мест размещения, тем более продолжительным является туристический сезон в них.

Таблица 3

Динамика занятости (\% 3) и среднее число дней эксплуатации (ДЭ) различных категорий МР в период 2010-2017 гг. (рассчитано автором)

\begin{tabular}{|l|c|c|c|c|c|c|}
\hline \multirow{2}{*}{ Категории МР } & \multicolumn{2}{c|}{2010} & \multicolumn{2}{c|}{2013} & \multicolumn{2}{c|}{2017} \\
\cline { 2 - 7 } & $\% 3$ & ДЭ & $\% 3$ & ДЭ & $\% 3$ & ДЭ \\
\hline Всего по стране, в т.ч: & 15,8 & 58 & 19,6 & 71 & 20,5 & 75 \\
\hline 4 и 5 звезды & 20,8 & 76 & 24,7 & 90 & 26,0 & 95 \\
\hline 3 звезды & 15,7 & 57 & 19,3 & 70 & 20,2 & 74 \\
\hline 1 и 2 звезды & 10,0 & 37 & 13,4 & 49 & 13,0 & 48 \\
\hline
\end{tabular}

Из краткого анализа воздействия сезонности на работу курортных комплексов Болгарии можно сделать следующие основные выводы:

- реальная продолжительность туристического сезона для дестинаций Болгарии примерно в два раза меньше, чем официально определено данными НСИ (около 100 дней) в последние годы, что ставит страну позади основных конкурентных дестинаций по этому показателю;

- в последние годы в Болгарии установилась постоянная, односторонняя тенденция уменьшения средней продолжительности туристического сезона; в отношении основных сезонных видов туризма наблюдаются неустановленные по направлению изменения;

- основными причинами негативных изменений в туристическом сезоне являются неустойчивое развитие болгарского туризма и отсутствие стратегии и решений для принятия адекватных политических и экономических мер по ограничению влияния сезонного фактора. 
Выводы и перспективы дальнейших разработок. На основе проведенного анализа и оценки сезонности предложены некоторые основные идеи и стратегические решения по продлению туристического сезона и, соответственно, увеличению занятости коечного фонда в болгарском туризме. Часть из них основана на прогнозах Всемирной туристической организации о развитии туризма до 2030 года, а другая - на анализе и оценках автора данной статьи [6].

Во-первых, необходима реальная диверсификация болгарского туристического продукта с целью увеличения относительной доли так называемых «круглогодичных» видов туризма и оптимальное сочетание и комбинирование продуктов традиционных массовых и сезонных видов туризма (морского, горного) с круглогодичными, такими как культурный, оздоровительный, спа-туризм, деловой, религиозный, азартный и др.).

Во-вторых, на рынке болгарских туристических продуктов необходимы расширение, диверсификация и реструктуризация спроса, в частности:

- разработка стратегического видения и мер по привлечению туристов из регионов, которые до 2030 года будут генерировать наивысший потенциал для туристических поездок в Европу и по всему миру (Китай, Индия, Япония и Вьетнам);

- разработка специализированных продуктов для новых целевых сегментов рынка, что предполагает акцентирование внимания на туристах «третьего возраста», с помощью которых можно продлить сезон, повысить платежеспособность посетителей и средний доход от них. Особое внимание следует обратить на потенциальных посетителей с ограниченными физическими возможностями и особыми потребностями, число которых достигнет около 127 млн. человек в 2020 году и которым потребуются специальные туристические услуги;

- реструктуризация туристической супер- и инфраструктуры и разнообразие предложений в неактивный туристический сезон с целью расширения возможностей для круглогодичного посещения туристами дестинаций для занятий культурным, спортивным, оздоровительным и другими альтернативными формами туризма; распространение модели «Камчия» для иностранных инвестиций в спортивную базу болгарского побережья Черного моря [7];

- разработка стратегии развития туризма в сельской местности и районах, бедных ресурсами для нужд других отраслей, но располагающих разнообразными условиями для новых видов и форм туризма.

В-третьих, необходимо усовершенствование системы территориального управления и регулирования развития туризма в Болгарии в рамках общей внутренней туристической политики. Основной стратегической задачей в данном случае является оценка факторов, которые оказывают наибольшее влияние на организацию и функции туристических территориальных структур (районов, областей, общин и населенных пунктов). Для решения этой задачи необходимы научно обоснованные и практически выполнимые методы для:

- точной идентификации территориальных различий в распределении и использовании туристических ресурсов и диверсификации предложения;

- системного и объективно измеримого эффекта от туризма в отдельных регионах с учетом влияния сезонного фактора и возможностей его ограничения;

- создания реальных возможностей для оптимизации целей и приоритетов развития туризма в соответствующем регионе и обеспечения процесса создания и реализации местных туристических продуктов.

В-четвертых, следует принять ряд политических мер для создания условий для продления туристического сезона. К ним можно отнести следующие:

- разработка долгосрочной национальной программы и отдельных программ для туристических зон с целью противодействия сезонности, которые должны быть политически, организационно и финансово обеспечены;

- активизация национальной рекламы и ее реализация через новые структуры управления туристическими регионами. При этом приоритетное внимание в рекламных кампаниях следует уделять возможностям формирования альтернативных туристических продуктов; 
- совершенствование системы статистического наблюдения и отчетности по результатам туристической деятельности; обновление нормативного регулирования развития туристических объектов, которые включаются в курорты национального значения (например, Банско);

- активизация общин, особенно в малых населенных пунктах, для поддержки инициатив связанных с развитием в них туризма; стимулирование малого и среднего бизнеса, партнерство между государственным и частным секторами в части ограничения воздействия сезонных факторов на туризм.

В-пятых, нуждается в совершенствовании законодательство о статусе сезонного работника и работника в сфере туризма; туристический сезон, как правило, длится не более чем 5-6 месяцев (в лучших случаях), что требует пересмотра указанного вопроса в кратчайшие сроки.

\section{Лuтература}

1. Ракаджийска С. Сезонност на туризма / Под общата ред. М. Нешкова // Въведение в туризма. Варна : Университетско издателство, 2001. С. 101-110.

2. Герасименко В. Г., Милашко О. Г. Методи статистичної оцінки сезонних коливань попиту на підприємствах туризму // Вісник соціально-економічних досліджень : зб. наук. праць. 1999. Вип. 3. С. 51-54.

3. Нешков М., Маринов С., Казанжиева В. Въведение в туризма. Варна : Наука и икономика, 2014. $350 \mathrm{c}$.

4. Начионален статистически институт Република България : статистически бюлетин. URL: http://www.nsi.bg/bg/content/1983 (дата на поискване: 10.10.2018).

5. Национален статистически институт Република България : статистически бюлетин. URL: http://www.nsi.bg/bg/content/1978 (дата на поискване: 11.10.2018).

6. UNWTO Tourism Highlights, 2017 Edition. URL: http://tourlib.net/wto/WTO_highlights_2017.pdf.

7. Национална стратегия за устойчиво развитие на туризма в Република България 2014-2030 г. URL: http://www.tourism.government.bg/sites/tourism.government.bg/files/uploads/strategy-policy/strategy_ 2014-2030_13_05_2014-sled_ms_26_05_2014.pdf (дата на поискване: 15.10.2018).

\section{References}

1. Rakadzhiyska, S. (2001). Seasonality in tourism. Ed. by M. Neshkov [Sezonnost na turizma; pod red. M. Neshkova], Universytetsko izdatelstvo, Varna, s. 101-110 [in Bulgarian]

2. Gerasymenko, V. G., Mylashko, O. G. (1999). Methods of statistical estimation in demand seasonal fluctuations at the tourism enterprises [Metody statystychnoi otsinky sezonnykh kolyvan popytu na pidpryiemstvakh turyzmu], Vìsnik socìal'no-ekonomičnih doslìdžen', Issue 3, s. 51-54 [in Ukrainian]

3. Neshkov, M., Marinov, S., Kazanzhieva, V. (2014). Introduction to tourism [Vvedenie v turizma], Nauka i ikonomika, Varna, $350 \mathrm{~s}$. [in Bulgarian]

4. National Statistical Institute of the Republic of Bulgaria: statistical bulletin [Natsionalen statisticheski institut Republika Blgariya: statisticheski byulletin], available at: http://www.nsi.bg/bg/content/1983 [in Bulgarian]

5. National Statistical Institute of the Republic of Bulgaria: statistical bulletin [Natsionalen statisticheski institut Republika Blgariya: statisticheski byulletin], available at: http://www.nsi.bg/bg/content/1978 [in Bulgarian]

6. UNWTO Tourism Highlights, 2017 Edition, available at: http://tourlib.net/wto/WTO_highlights_2017.pdf.

7. National Strategy for tourism sustainable development in the Republic of Bulgaria 2014-2030 [Natsionalna strategiya za ustoychivo razvitie na turizma v Republika Blgariya 2014-2030 g.], available at: http://www.tourism.government.bg/sites/tourism.government.bg/files/uploads/strategypolicy/strategy_ 2014-2030_13_05_2014-sled_ms_26_05_2014.pdf [in Bulgarian] 